\title{
(n) open Use of selective serotonin reuptake inhibitors and lifestyle among women of childbearing age: a Danish cross- sectional survey
}

\author{
Kristina Laugesen, ${ }^{1}$ Ane Birgitte Telén Andersen, ${ }^{1}$ Mette Nørgaard, ${ }^{1}$ \\ Rikke Beck Nielsen, ${ }^{1}$ Reimar Wernich Thomsen, ${ }^{1}$ Finn Breinholt Larsen, ${ }^{2}$ \\ Henrik Toft Sørensen ${ }^{1}$
}

To cite: Laugesen $\mathrm{K}$, Telén Andersen AB, Nørgaard M, et al. Use of selective serotonin reuptake inhibitors and lifestyle among women of childbearing age: a Danish cross-sectional survey. BMJ Open 2013;3:e003024. doi:10.1136/bmjopen-2013003024

- Prepublication history and additional material for this paper is available online. To view these files please visit the journal online (http://dx.doi.org/10.1136/ bmjopen-2013-003024).

Received 9 April 2013 Revised 7 June 2013 Accepted 27 June 2013

${ }^{1}$ Department of Clinical Epidemiology, Institute of Clinical Medicine, Aarhus University Hospital, Aarhus, Denmark

${ }^{2}$ Public Health and Quality Improvement, Central Denmark Region, Aarhus, Denmark

\section{Correspondence to} Kristina Laugesen; kristina. laugesen@studmed.au.dk

\section{ABSTRACT}

Objective: To examine the use of selective serotonin reuptake inhibitors (SSRIs) among Danish women of childbearing age according to lifestyle factors.

Design: Cross-sectional survey.

Setting: The Central Denmark Region.

Participants: 4234 women $(71.5 \%$ of the invited women) aged 25-44 years who participated in a public health survey in 2006.

Outcome measures: Prevalence and prevalence ratios (PRs) of current and former SSRI use among women characterised by selected lifestyle factors. We obtained information on SSRI use through linkage to the Aarhus University Prescription Database covering all pharmacies in the region.

Results: Of the 4234 women in the study, 161 (3.8\%) were current SSRI users, 60 (1.4\%) were recent users, $223(5.3 \%)$ were former users and $3790(89.5 \%)$ were never users. Current use of SSRIs was more prevalent in obese women than in non-obese women (PR 1.5, $95 \% \mathrm{Cl} 1.0$ to 2.3), in current smokers compared with non-current smokers (PR 1.6, $95 \% \mathrm{Cl} 1.1$ to 2.2), in women who drank more than seven alcoholic drinks weekly compared with women who drank seven or fewer drinks weekly (PR 1.8, 95\% $\mathrm{Cl} 1.2$ to 2.8 ) and in women with an unhealthy diet compared with women with a healthy diet (PR 1.7, 95\% Cl 1.2 to 2.6 ). Prevalence of former use of SSRIs was similarly increased except in those with an unhealthy diet (PR $1.1,95 \% \mathrm{Cl} 0.8$ to 1.7$)$. SSRI use did not differ according to participation in regular physical activity. Conclusions: Women with an unhealthy lifestyle were about 1.5-fold more likely to be current or former users of SSRIs than those with a healthy lifestyle. These findings may be useful for quantitative assessment of the contribution of lifestyle factors to uncontrolled confounding in studies of SSRI use in pregnancy.

\section{INTRODUCTION}

More than $10 \%$ of pregnant women experience depression. ${ }^{1}$ In deciding to initiate

\section{ARTICLE SUMMARY}

Article focus

- To examine whether current and former use of selective serotonin reuptake inhibitors (SSRIs) differ according to lifestyle factors among women of childbearing age.

Key messages

- Of the 4234 women aged 25-44 years participating in a public health survey, $161(3.8 \%)$ were current SSRI users, $60(1.4 \%)$ were recent users and $223(5.3 \%)$ were former users.

- Current and former uses of SSRIs were at least 1.5 -fold or more prevalent in women who were obese, who were current smokers or who had a weekly alcohol intake above seven drinks, as compared with women with a healthier lifestyle. Current but not former use of SSRIs was more common in women with an unhealthy diet and in women with intake of alcohol of more than 14 drinks weekly. SSRI use did not differ much according to participation in regular physical activity.

Strengths and limitations of this study

- SSRI use was identified from a comprehensive population-based prescription database, thus eliminating recall bias. The high quality and completeness of data in this database have been documented. Detailed information on lifestyle factors was available from questionnaires.

- Because the study was based on volunteers in a health survey (participation rate of women of childbearing age was $71.5 \%$ ), participants may have been more health conscious than non-participants.

- Filled prescriptions may not be an entirely perfect measure of actual drug intake and its timing and thus may have led to some misclassification of SSRI use.

antidepressant drug treatment in pregnant women, the potential negative effects of untreated depression on the mother and 
fetus $^{2-6}$ must be weighed against the risk of adverse pregnancy outcomes associated with in utero exposure to antidepressant drugs. ${ }^{2}$

Selective serotonin reuptake inhibitors (SSRIs) constitute the most commonly used class of antidepressants. The use of these drugs has substantially increased ${ }^{78}$ in recent years. In Denmark, 2.4\% of all pregnant women were treated with SSRIs in 2006, compared with $0.3 \%$ in $1997 .^{9}$

In a number of studies, SSRI use has been associated with adverse pregnancy outcomes, including preterm birth, poor neonatal adaptation, low birth weight, persistent pulmonary hypertension and cardiac malformations. ${ }^{10-15}$ One study reported an elevated risk of cardiac malformations after prenatal exposure to SSRI, but concluded that this was due to unaccounted confounding. ${ }^{15}$ However, other studies did not find such associations. ${ }^{16} 17$ Studies investigating these associations often have lacked information on maternal lifestyle factors, such as smoking, ${ }^{10}$ alcohol consumption ${ }^{12-14}$ and body mass index (BMI). ${ }^{101314}$ Thus, they may have been biased by uncontrolled confounding, complicating the interpretation of their results.

Unhealthy lifestyle choices during pregnancy, including smoking, alcohol consumption and obesity, are known to be associated with increased risk of adverse pregnancy outcomes. ${ }^{18-21}$ Still, few studies have investigated whether use of antidepressants differs according to lifestyle factors. Available studies have reported that depression and antidepressant use are more frequent among smokers, alcohol consumers and obese people. ${ }^{22-24}$ In the current study, we used data from a Danish public health survey to examine the relation between SSRI use and lifestyle among women of childbearing age.

\section{METHODS}

Study design

We conducted a cross-sectional study based on a 2006 public health survey administered in the Central Denmark region.

\section{Setting}

Denmark has 5.5 million inhabitants and is administratively divided into five regions. We conducted this study in one of these regions, the Central Denmark Region, with a population of about 1.2 million people. The Danish healthcare system provides tax-supported healthcare to all residents, guaranteeing free and unfettered access to primary and secondary care. Except for emergencies, general practitioners (GPs) are the patients' initial contact with the healthcare system. GPs either treat the patients themselves or refer them to hospitals or specialists in the primary healthcare sector.

The unique 10-digit central personal registry number (CPR number) assigned to each Danish citizen at birth and to residents upon immigration ${ }^{25}$ allows accurate and unambiguous linkage of all medical and administrative registries at the individual level in Denmark.

\section{Study population}

The study population was identified through the survey, "Hvordan har du det?"/"How Are You?", a questionnaire-based public health study conducted by the Centre for Public Health (now Centre for Public Health and Quality Improvement), Central Denmark Region. In 2006, a random sample of 31500 people living in the region was invited to participate in the study. Eligible participants, identified through the Civil Registration System, were 25-79 years of age, residents of the Central Denmark Region, and Danish citizens with at least one parent born in Denmark. In total, 21708 $(69 \%)$ invited persons agreed to participate. A questionnaire and a stamped return envelope were delivered by mail. In order to maximise participation, ${ }^{26}$ three reminders were sent to non-respondents. Those who agreed to participate completed a detailed questionnaire containing approximately 400 questions on self-rated health, occurrence of chronic diseases, socioeconomic factors and lifestyle factors. The current study was based on a subsample of female respondents of childbearing age, defined as age 25-44 years. In this subsample, 4234 $(71.5 \%)$ of the invited women agreed to participate.

The survey has been described in detail elsewhere (available in Danish: http://www.cfk.rm.dk/udgivelser/ befolkningsundersøgelser).

\section{Data on lifestyle factors}

Lifestyle factors included in the study were BMI, participation in regular physical activity, diet, smoking status and alcohol intake.

BMI was calculated as self-reported weight in kilograms divided by self-reported height in $\mathrm{m}^{2}$. BMI was categorised according to the WHO criteria as underweight $(\mathrm{BMI}<18.5)$, normal weight (BMI 18.5-24.99), overweight (BMI 25-29.99) and obese (BMI $\geq 30) .{ }^{27}$ The physical activity questionnaire asked participants questions relating to participation in leisure sports or other regular physical activity (yes/no). To assess diet, this health survey used a score system developed by the Research Centre for Prevention and Health, the Capital Region of Denmark. ${ }^{28}$ This included 30 different questions regarding intake of fruit, vegetables, fish and fat. By the score system, the responses were summarised into categories of healthy (high amount of fruit, vegetables, fish and low amount of saturated fat), reasonably healthy (median high intake of fruit, vegetables, fish and saturated fat) or unhealthy diet (low amount of fruit, vegetables, fish and high amount of saturated fat). Smoking status was categorised as never, former and current (daily or occasional) tobacco smoking. Finally, the alcohol use questionnaire asked participants how many drinks per week they consumed. First, we categorised alcohol use according to the Danish Health and Medicine Authority's recommendations, that is, higher 
than recommended (>seven drinks weekly) or within the recommended guidelines ( $\leq$ seven drinks weekly). ${ }^{29}$ Second, we categorised alcohol as $>14$ drinks weekly and $\leq 14$ drinks weekly.

\section{Data on SSRI and antiepileptic, antidiabetics and} antipsychotic use

In Denmark, antidepressants are available on prescription only. All pharmacies in the Central Denmark Region are equipped with a computerised accounting system that transmits data to the Danish Health Service for reimbursement of prescribed drugs. According to an agreement with Aarhus University, the National Health Service subdivision of the Central Denmark Region transfers individually identifiable prescription redemption data from the pharmacies to the Aarhus University Prescription Database (AUPD). The AUPD contains information on the CPR number of the patient, the type of drug prescribed according to name and the Anatomical Therapeutic Chemical (ATC) classification system, and the date the prescription was redeemed. ${ }^{30}$ Data are available from 1996 onwards. In Denmark, a prescription for SSRI generally lasts between 28 and 100 days, given that the daily use is one DDD. We classified current users of SSRIs (ATC code N06AB) as those who redeemed at least one prescription within 90 days before and up to 30 days after completing the survey questionnaire. We defined recent users as those who redeemed an SSRI prescription in the period from 365 until 91 days before completing the questionnaire. Former users were those who redeemed at least one SSRI prescription more than 365 days before completing the questionnaire but had no prescriptions within 365 days before and up to 30 days after questionnaire completion. Never users were defined as women who never had a prescription for an SSRI.

We further defined use of antidiabetic (ATC code A10), antiepileptic (ATC code N03) and antipsychotic (ATC code N05A) drugs as ever having redeemed a prescription on these drugs before filling in the questionnaire.

\section{Statistical analyses}

We computed the prevalence of SSRI use (current, former, recent and never use) according to the available lifestyle factors and according to the use of antidiabetic, antiepileptic and antipsychotic drugs. We then calculated prevalence ratios (PRs) and 95\% CIs using the Clopper-Pearson exact method for current SSRI use and former SSRI use, comparing obese women (BMI $\geq 30)$ with non-obese women $(\mathrm{BMI}<30)$, current smokers with non-current smokers (never and former smokers), women with alcohol intake of more than seven drinks weekly with women with alcohol intake of seven drinks or less weekly, women with alcohol intake of more than 14 drinks with women with alcohol intake of 14 drinks or less weekly, women with an unhealthy diet with women with a healthy diet (healthy and reasonably healthy) and women who participated in regular physical activity with women who did not. Women with missing data were excluded from the analyses.

In a sensitivity analysis, we added recent SSRI users to the group of current users and estimated PRs for current/recent use with $95 \%$ CIs associated with lifestyle factors. This analysis was undertaken to investigate whether potential misclassification between current and recent users could have affected our estimates.

All statistical analyses were conducted using Stata software (Release V.12, StataCorp LP).

\section{RESULTS}

In total, 4234 women (71.5\% of those invited) aged 2544 years participated in the survey. Of these, $161(3.8 \%)$ were current SSRI users, 223 (1.4\%) were former users, $60(5.3 \%)$ were recent users and 3790 (89.5\%) were never users. We investigated the number of pregnant women in our study population as the number of women who gave birth up to 9 months after filling in the questionnaire. In total, we identified 232 pregnant women. Among these, $3(1.3 \%)$ were current users, $3(1.3 \%)$ were recent users and $11(4.7 \%)$ were former users. The small number of pregnant women in our study population did not allow us to examine the relation between use of SSRI and lifestyle factors in pregnancy. Table 1 shows the distribution of SSRI use (current, recent, former and never use) according to lifestyle factors and use of antidiabetic, antiepileptic and antipsychotic drugs.

Table 2 shows PRs for current, current/recent and former use of SSRIs according to the lifestyle factors. Obese women had a higher prevalence of current SSRI use than non-obese women (PR 1.5, 95\% CI 1.0 to 2.3). Current smokers had a higher prevalence of current SSRI use than non-current smokers (PR 1.6, 95\% CI 1.1 to 2.2). Women with an intake of alcohol of more than seven drinks weekly had a higher prevalence of current SSRI use than women whose weekly alcohol intake was seven drinks or less (PR 1.8, 95\% CI 1.2 to 2.8). Using 14 drinks/week as the level for overuse, there was an increase in PR (PR 2.9, 95\% CI 1.7 to 5.3). Women with an unhealthy diet had a higher prevalence of current SSRI use than women with a healthy diet (PR 1.7, 95\% CI 1.2 to 2.6$)$. Women who participated in regular physical activity and women who did not participate in regular physical activity had a similar prevalence of current SSRI use. The prevalence of former SSRI use by lifestyle factors followed the same pattern as current use. The only exception was unhealthy diet (PR 1.1, 95\% CI 0.8 to 1.7$)$ and alcohol intake of more than 14 drinks weekly (PR 1.1, 95\% CI 0.5 to 2.6).

In the sensitivity analysis, which added recent users to the group of current users, PRs for SSRI use were very similar to those in the main analysis (table 2).

\section{DISCUSSION}

In our study, women with unhealthy lifestyles were more often current or former users of SSRIs compared with 
Table 1 Distribution of selective serotonin reuptake inhibitor (SSRI) use in women aged 25-44 years according to lifestyle factors

\begin{tabular}{|c|c|c|c|c|c|}
\hline & $\begin{array}{l}\text { Current use of } \\
\text { SSRIs, N (\%) }\end{array}$ & $\begin{array}{l}\text { Recent use of } \\
\text { SSRIs, N (\%) }\end{array}$ & $\begin{array}{l}\text { Former use of } \\
\text { SSRIs, N (\%) }\end{array}$ & $\begin{array}{l}\text { Never use of } \\
\text { SSRIs, N (\%) }\end{array}$ & Total, N (\%) \\
\hline Number of women & $161(3.8)$ & $60(1.4)$ & $223(5.3)$ & 3790 (89.5) & $4234(100)$ \\
\hline Median age (range of age) & $38.0(25.4-44.9)$ & $34.6(25.3-44.9)$ & $39.0(25.3-44.9)$ & $36.8(25.1-44.9)$ & $36.9(25.1-44.9)$ \\
\hline \multicolumn{6}{|c|}{ (1) } \\
\hline$<18.5$ & $5(5.1)$ & $3(3.1)$ & $3(3.1)$ & 87 (88.8) & $98(100)$ \\
\hline $18.5-24.9$ & $72(3.0)$ & $36(1.5)$ & $128(5.2)$ & 2245 (90.5) & $2481(100)$ \\
\hline $25.0-29.9$ & $49(4.9)$ & $11(1.1)$ & $47(4.7)$ & 890 (89.3) & $997(100)$ \\
\hline$\geq 30.0$ & $30(5.3)$ & $8(1.4)$ & $38(6.8)$ & $486(86.5)$ & $562(100)$ \\
\hline Missing & $5(5.2)$ & $2(2.1)$ & 7 (7.3) & $82(85.4)$ & $96(100)$ \\
\hline \multicolumn{6}{|l|}{ Smoking } \\
\hline Current & $44(5.1)$ & $20(2.3)$ & $67(7.8)$ & $725(84.7)$ & $856(100)$ \\
\hline Former & $33(3.2)$ & $12(1.2)$ & $59(5.5)$ & $912(89.8)$ & $1016(100)$ \\
\hline Never & $82(3.5)$ & $27(1.2)$ & $95(4.1)$ & $2136(91.3)$ & 2340 (100) \\
\hline Missing & $2(9.1)$ & $1(4.5)$ & $2(9.1)$ & 17 (77.3) & $22(100)$ \\
\hline \multicolumn{6}{|l|}{ Diet } \\
\hline Unhealthy & $26(6.1)$ & $12(2.8)$ & $24(5.6)$ & 366 (85.5) & $428(100)$ \\
\hline Reasonably healthy & $95(3.5)$ & $33(1.2)$ & $144(5.3)$ & 2465 (90.1) & 2737 (100) \\
\hline Healthy & $38(3.8)$ & $14(1.4)$ & $48(4.8)$ & $895(90.0)$ & $995(100)$ \\
\hline Missing & $2(1.5)$ & $59(44.7)$ & $7(5.3)$ & $64(48.5)$ & $132(100)$ \\
\hline \multicolumn{6}{|l|}{ Intake of alcohol } \\
\hline More than seven drinks weekly & $23(6.3)$ & $2(0.5)$ & $23(6.3)$ & $320(87.0)$ & $368(100)$ \\
\hline Seven drinks or less weekly & $124(3.5)$ & $49(1.4)$ & $165(4.7)$ & $3197(90.4)$ & 3535 (100) \\
\hline More than 14 drinks weekly & $11(10.6)$ & $1(1.0)$ & $5(4.8)$ & 87 (83.7) & $104(100)$ \\
\hline 14 drinks or less weekly & $136(3.6)$ & $50(1.3)$ & $183(4.8)$ & 3430 (90.3) & 3799 (100) \\
\hline Missing & $14(4.2)$ & $9(2.7)$ & $35(10.6)$ & $273(82.5)$ & $331(100)$ \\
\hline \multicolumn{6}{|c|}{ Participation in regular physical activity } \\
\hline Yes & 77 (3.6) & $24(1.1)$ & $102(4.8)$ & 1935 (90.5) & $2138(100)$ \\
\hline No & $83(4.1)$ & $35(1.7)$ & $119(5.8)$ & $1803(88.4)$ & 2040 (100) \\
\hline Missing & $1(1.8)$ & $1(1.8)$ & $2(3.6)$ & 52 (92.9) & $56(100)$ \\
\hline \multicolumn{6}{|l|}{ Use of drugs other than SSRI } \\
\hline Antidiabetic drugs & $1(2.1)$ & $2(4.3)$ & $4(8.5)$ & $40(85.1)$ & $47(100)$ \\
\hline Antiepileptic drugs & 12 (15.2) & $7(8.9)$ & $20(25.3)$ & $40(50.6)$ & 79 (100) \\
\hline Antipsychotic drugs & $30(31.6)$ & $3(3.2)$ & $32(33.7)$ & $30(31.6)$ & 95 (100) \\
\hline
\end{tabular}

Diet: healthy (high amount of fruit, vegetables, fish and low amount of saturated fat), reasonably healthy (median high amount of fruit, vegetables, fish and saturated fat) or unhealthy diet (low amount of fruit, vegetables, fish and high amount of saturated fat).

Participation in regular physical exercise: the physical activity questionnaire asked questions regarding participation in leisure sports or other regular physical activity (yes/no).

women with healthier lifestyles. However, the prevalence of current and former SSRI use among women not participating in regular physical activity was similar to that among women who participated in regular physical activity. Current but not former use of SSRIs was more common in women with an unhealthy diet and an alcohol intake of more than 14 drinks weekly. Our study contributes to knowledge of how use of SSRIs differs according to lifestyle choices among women of childbearing age.

Our study differs from earlier studies ${ }^{22-24}$ by focusing on women of childbearing age. Therefore, our findings are applicable for assessing potential confounding in studies of birth outcomes in women using SSRIs.

However, our findings are in line with the previous findings in populations consisting of men and women, thus underlining the reliability of our results. A French questionnaire-based public health survey including
10252 men and women aged over 18 years found that non-smokers and former smokers had a $30 \%$ lower risk of being prescribed an antidepressant than current smokers. ${ }^{24}$ An American study including 43093 men and women found that abusers of alcohol had an increased risk of major depression compared with lifetime abstainers ((OR 2.1, 95\% CI 1.3 to 3.4) for young adults not attending college and OR $1.3,95 \%$ CI 1.0 to 1.6 for adults over the age of 30 years, respectively). ${ }^{22}$ Also, a meta-analysis including in total 58745 men and women found that obese persons were at increased risk of developing depression over time (pooled OR 1.55, $95 \%$ CI 1.23 to 2.01$){ }^{23}$

We identified use of SSRIs from a comprehensive population-based prescription database, thus eliminating recall bias. This database is considered to be complete regarding SSRIs, as SSRIs are available by prescription only and therefore not sold as over-the-counter drugs. ${ }^{30}$ 
Table 2 Prevalence ratios (PRs) and 95\% Cls for the use of selective serotonin reuptake inhibitors (SSRIs) in women aged 25-44 years, according to different lifestyle factors

\begin{tabular}{|c|c|c|c|c|c|c|}
\hline $\begin{array}{l}\text { SSRI } \\
\text { use }\end{array}$ & $\begin{array}{l}\text { PRs } \\
\text { comparing } \\
\text { obese vs } \\
\text { non-obese } \\
\text { women (95\% } \\
\text { Cls) }\end{array}$ & $\begin{array}{l}\text { PRs comparing } \\
\text { current } \\
\text { smokers vs } \\
\text { non-current } \\
\text { smokers ( } 95 \% \\
\text { Cls) }\end{array}$ & $\begin{array}{l}\text { PRs comparing } \\
\text { alcohol intake } \\
\text { above seven } \\
\text { drinks weekly vs } \\
\text { alcohol intake of } \\
\text { seven drinks or } \\
\text { less weekly ( } 95 \% \\
\text { Cls) }\end{array}$ & $\begin{array}{l}\text { PRs comparing } \\
\text { alcohol intake } \\
\text { above } 14 \text { drinks } \\
\text { weekly vs } \\
\text { alcohol intake of } \\
14 \text { drinks or less } \\
\text { weekly ( } 95 \% \text { Cls) }\end{array}$ & $\begin{array}{l}\text { PRs } \\
\text { comparing } \\
\text { unhealthy } \\
\text { diet vs } \\
\text { healthy diet } \\
\text { (95\% Cls) }\end{array}$ & $\begin{array}{l}\text { PRs comparing } \\
\text { participation in } \\
\text { regular activity vs } \\
\text { not participation } \\
\text { in regular activity } \\
(95 \% \mathrm{Cls})\end{array}$ \\
\hline $\begin{array}{l}\text { Never } \\
\text { use }\end{array}$ & 1 (reference) & 1 (reference) & 1 (reference) & 1 (reference) & 1 (reference) & 1 (reference) \\
\hline $\begin{array}{l}\text { Current } \\
\text { use }\end{array}$ & 1.5 (1.0 to 2.3 ) & 1.6 (1.1 to 2.2$)$ & 1.8 (1.2 to 2.8$)$ & 2.9 (1.7 to 5.3$)$ & 1.7 (1.2 to 2.6$)$ & 0.9 (0.6 to 1.2$)$ \\
\hline $\begin{array}{l}\text { Current/ } \\
\text { recent } \\
\text { use }\end{array}$ & $1.4(1.0$ to 2.0$)$ & 1.7 (1.3 to 2.2 ) & $1.4(0.9$ to 2.1$)$ & $2.4(1.4$ to 4.1$)$ & 1.8 (1.3 to 2.6$)$ & 0.8 (0.6 to 1.0$)$ \\
\hline $\begin{array}{l}\text { Former } \\
\text { use }\end{array}$ & $1.4(1.0$ to 1.9$)$ & 1.8 (1.3 to 2.3 ) & $1.4(0.9$ to 2.1$)$ & 1.1 (0.5 to 2.6) & $1.1(0.8$ to 1.7$)$ & 0.8 (0.6 to 1.0$)$ \\
\hline
\end{tabular}

Furthermore, our use of questionnaires permitted collection of detailed information on the selected lifestyle factors.

Our study also has limitations. The study was crosssectional and based on responses of women who volunteered to participate in a health survey. Because participants in such surveys might be more health conscious than non-participants, our cohort may not be representative of lifestyle choices in the general population. Survey participation was $69 \%$ overall and $71.5 \%$ among women aged 25-44 years. It is possible that nonparticipants may have differed from participants not only in lifestyle but also in the prevalence of major depression. This may have led us to underestimate the prevalence of SSRI use among women with unhealthy lifestyles. Furthermore, as information on lifestyle factors was self-reported, it is possible that unhealthy lifestyles were under-reported. It is possible that women who are depressed/using SSRIs may report lifestyle factors differently than other women and that such a potential misclassification may affect our results.

Also, redeemed prescriptions may be an imperfect measure of actual drug intake and timing. This may have led to the misclassification of some non-users as SSRI users due to non-compliance. While this would not explain our finding of a higher prevalence of current SSRI use among women with an unhealthy lifestyle, it could have led us to underestimate the association.

The results of this cross-sectional survey may be useful in quantifying the degree to which uncontrolled confounding by lifestyle factors may affect studies of SSRI use during pregnancy. However, it must be noted that women might alter their lifestyle in terms of alcohol use, smoking and diet before or during pregnancy, and thus the results may not be applicable to all pregnant women.

In conclusion, women with an unhealthy lifestyle were about 1.5-fold more likely to be current or former SSRI users than women with a healthier lifestyle.

Acknowledgements We would like to thank all the participants who helped us in conducting this study by completing the questionnaires.

Contributors $\mathrm{KL}, \mathrm{ABTA}$ and MN made primary contributions to the writing of the manuscript. RBN contributed to data collection and $\mathrm{KL}$ was involved in statistical analyses. All authors contributed to the study conception, design and interpretation of results, revised the manuscript critically and approved the final version of the manuscript.

Funding This research was supported by the Clinical Epidemiology Research Foundation, Aarhus University Hospital, Aarhus, Denmark. The Department of Clinical Epidemiology, Aarhus University Hospital, receives funding for other studies from companies in the form of research grants to (and administered by) Aarhus University.

Competing interests None.

Ethics approval The study was approved by the Danish Data Protection Agency (Record no. 2009-41-3866). As it does not include human biological material, approval by the Danish Scientific Ethical Committee is not needed according to Danish legislation.

Provenance and peer review Not commissioned; externally peer reviewed.

Data sharing statement No additional data are available.

Open Access This is an Open Access article distributed in accordance with the Creative Commons Attribution Non Commercial (CC BY-NC 3.0) license, which permits others to distribute, remix, adapt, build upon this work noncommercially, and license their derivative works on different terms, provided the original work is properly cited and the use is non-commercial. See: http:// creativecommons.org/licenses/by-nc/3.0/ 


\section{REFERENCES}

1. Bennett HA, Einarson A, Taddio A, et al. Prevalence of depression during pregnancy; systematic review. Obstet Gynecol 2004;103:698-709.

2. Bennett HA, Einarson A, Taddio A, et al. Depression during pregnancy: overview of clinical factors. Clin Drug Investig 2004;24:157-79.

3. Zuckerman $\mathrm{B}$, Amaro $\mathrm{H}$, Baucher $\mathrm{H}$, et al. Depressive symptoms during pregnancy: relationship to poor health behaviors. Am J Obstet gynecol 1989;160:1107-11.

4. Lejoyeux M, Leon E, Rouillon F. Prevalence and risk factors of suicide and attempted suicide. Encephale 1994;20:495-503.

5. Bonari L, Pinto N, Ahn E, et al. Perinatal risks of untreated depression during pregnancy. Can J Psychiatry 2004;49: 726-35.

6. Grote NK, Bridge JA, Gavin AR, et al. A meta-analysis of depression during pregnancy and the risk of preterm birth, low birth weight, and intrauterine growth restriction. Arch Gen Psychiatry 2010;67:1012-24

7. Cooper WO, Willy ME, Pont SJ, et al. Increasing use of antidepressants in pregnancy. Am J Obstet Gynecol 2007;196:544. e1-5.

8. Andrade SE, Raebel MA, Brown J, et al. Use of antidepressant medications during pregnancy: a multisite study. Am J Obstet Gynecol 2008;198:194.e1-5.

9. http://www.sst.dk/Nyhedscenter/Nyheder/2007/nye_tal_20-07.aspx (accessed 29 Mar 2013)

10. Wen SW, Yang Q, Garner P, et al. Selective serotonin reuptake inhibitors and adverse pregnancy outcomes. Am J Obstet Gynecol 2006;194:961-6.

11. Lund N, Pedersen LH, Henriksen TB. Selective serotonin reuptake inhibitor exposure in utero and pregnancy outcomes. Arch Pediatr Adolesc Med 2009;163:949-54.

12. Reis M, Kallen B. Delivery outcome after maternal use of antidepressant drugs in pregnancy: an update using Swedish data. Psychol Med 2010;40:1723-33.

13. Pedersen LH, Henriksen TB, Vestergaard M, et al. Selective serotonin reuptake inhibitors in pregnancy and congenital malformations: population based cohort study. BMJ 2009;339: b3569.

14. Kieler H, Artama M, Engeland A, et al. Selective serotonin reuptake inhibitors during pregnancy and risk of persistent pulmonary hypertension in the newborn: population based cohort study from the five Nordic countries. BMJ 2012;339:d8012.

15. Jimenez-Solem E, Andersen JT, Petersen M, et al. Exposure to selective serotonin reuptake inhibitors and the risk of congenital malformations: a nationwide cohort study. BMJ Open 2012;2: e001148.

16. Reis $\mathrm{M}$, Kallen $\mathrm{B}$. Combined use of selective serotonin reuptake inhibitors and sedatives/hypnotics during pregnancy: risk of relatively severe congenital malformations or cardiac defects: a register study. BMJ Open 2013;3:e002166.

17. Alwan S, Reefhuis J, Rasmussen SA, et al. Use of selective serotonin-reuptake inhibitors in pregnancy and the risk of birth defects. N Engl J Med 2007;356:2684-92.

18. Rogers JM. Tobacco and pregnancy: overview of exposures and effects. Birth Defects Res C Embryo Today 2008;84:1-15.

19. Dennedy MC, Avalos G, ÓReilly MW, et al. The impact of maternal obesity on gestational outcomes. Ir Med J 2012;105:23-5.

20. Erickson AC, Arbour LT. Heavy smoking during pregnancy as a marker for other risk factors of adverse birth outcomes: a population-based study in British Columbia, Canada. BMC Public Health 2012;12:102.

21. Mateja WA, Nelson DB, Kroelinger CD, et al. The association between maternal alcohol use and smoking in early pregnancy and congenital cardiac defects. J Womens Health (Larchmt) 2012;21:26-34

22. Dawson DA, Grant BF, Stinson FS, et al. Psychopathology associated with drinking and alcohol use disorders in the college and general adult populations. Drug Alcohol Depend 2005;77:139-50.

23. Luppino FS, De Wit LM, Bouvy PF, et al. Overweight, obesity, and depression: a systematic review and meta-analysis of longitudinal studies. Arch Gen Psychiatry 2010;67:220-9.

24. Cheron-Launay M, Le Faou AL, Sevilla-Dedieu C, et al. Smoking and the consumption of antidepressants, anxiolytics and hypnotic drugs: results of a large, French epidemiological study in 2005. Addict Behav 2011;36:743-8.

25. Pedersen CB. The Danish Civil Registration System. Scand J Public Health 2011;39:22-5.

26. Edwards $\mathrm{P}$, Roberts I, Clarke $\mathrm{M}$, et al. Increasing response rates to postal questionnaires: systematic review. BMJ 2002;324:1183.

27. http://apps.who.int/bmi/index.jsp?introPage=intro_3.html (accessed 29 Mar 2013).

28. Toft U, Kristoffersen LH, Lau C, et al. The Dietary Quality Score: validation and association with cardiovascular risk factors: the Inter99 study. Eur J Clin Nutr 2007;61:270-8.

29. http://www.sst.dk/Sundhed\%20og\%20forebyggelse/Alkohol.aspx (accessed 28 May 2013)

30. Ehrenstein V, Antonsen S, Pedersen L. Existing data sources for clinical epidemiology: Aarhus University Prescription Database. Clin Epidemiol 2010;2:273-9. 